\title{
BMJ Open Prevalence of abdominal obesity and its association with cardiovascular risk among the adult population in Burkina Faso: findings from a nationwide cross- sectional study
}

\author{
Kadari Cisse (1) , ${ }^{1,2}$ Sékou Samadoulougou (1) , ${ }^{3}$ Mady Ouedraogo, ${ }^{4}$ \\ Seni Kouanda (D) , ${ }^{2,5}$ Fati Kirakoya-Samadoulougou (D) ${ }^{1}$
}

\section{To cite: Cisse $\mathrm{K}$,}

Samadoulougou S, Ouedraogo M et al. Prevalence of abdominal obesity and its association with cardiovascular risk among the adult population in Burkina Faso: findings from a nationwide cross-sectional study. BMJ Open 2021;11:e049496. doi:10.1136/ bmjopen-2021-049496

- Prepublication history for this paper is available online. To view these files, please visit the journal online (http://dx.doi. org/10.1136/bmjopen-2021049496).

Received 25 January 2021 Accepted 18 June 2021
Check for updates

(C) Author(s) (or their employer(s)) 2021. Re-use permitted under CC BY-NC. No commercial re-use. See rights and permissions. Published by BMJ.

For numbered affiliations see end of article.

Correspondence to

Dr Kadari Cisse;

cisskad4@gmail.com

\section{ABSTRACT}

Objective The objective of this study is to determine the prevalence of abdominal obesity, its predictors and its association with cardiovascular risk among adults in Burkina Faso.

Design We performed a secondary analysis of data from a national cross-sectional study, using WHO STEPwise approach.

Setting The study was conducted in Burkina Faso, in all the 13 regions of the country.

Participants Our study involved 4308 adults of both sexes, aged between 25 and 64 years.

Primary and secondary outcomes Our primary outcome was abdominal obesity, which was defined using a cut-off point of waist circumference (WC) of $\geq 94 \mathrm{~cm}$ for men and $\geq 80 \mathrm{~cm}$ for women. The secondary outcome was very high WC ( $\geq 102 \mathrm{~cm}$ for men and $\geq 88 \mathrm{~cm}$ for women) (for whom weight management is required).

Results The mean age of participants was $38.5 \pm 11.1$ years. The age-standardised prevalence of abdominal obesity was $22.5 \%$ (95\% Cl $21.3 \%$ to $23.7 \%)$. This prevalence was $35.9 \%$ (95\% Cl $33.9 \%$ to $37.9 \%$ ) among women and $5.2 \%$ (95\% Cl $4.3 \%$ to $6.2 \%$ ) among men. In urban areas, the age-standardised prevalence of abdominal obesity was $42.8 \%$ (95\% Cl $39.9 \%$ to $45.7 \%)$ and $17.0 \%(95 \% \mathrm{Cl} 15.7 \%$ to $18.2 \%)$ in rural areas. The age-standardised prevalence of very high WC was $10.2 \%$ (95\% Cl $9.3 \%$ to $11.1 \%)$. The main predictors of abdominal obesity were being female, increased age, married status, high level of education and living in urban areas. Abdominal obesity was also significantly associated with high blood pressure (adjusted prevalence ratio (aPR): 1.30; $95 \% \mathrm{Cl} 1.14$ to 1.47 ) and hypercholesterolaemia (aPR: 1.52; $95 \% \mathrm{Cl} 1.18$ to 1.94). According to the combination matrix between body mass index and WC, $14.6 \%$ of the adult population in Burkina Faso had an increased cardiometabolic risk.

Conclusion Our study showed a high prevalence of abdominal obesity and a high proportion of adults who require weight management strategies to prevent cardiometabolic complications. Strategies to reduce the burden of abdominal obesity and very high WC should be considered by Burkina Faso's policy-makers.
Strengths and limitations of this study

- To the best of our knowledge, this study is the first national representative study on abdominal obesity within the adult population of Burkina Faso.

- The waist circumference and risk factors used in this study were measured using the WHO STEPwise standard approach.

- Behavioural risk factors such as physical inactivity, alcohol consumption and type of fat may be affected by social desirability bias and recall bias.

- The measurement of the waist circumference only once might cause measurement bias.

- This study was a cross-sectional study and cannot be used to derive causal inference.

\section{INTRODUCTION}

Obesity is an increasing public health issue worldwide, particularly in low/middle-income countries. Globally, 603.7 million adults were found to be obese in 2015 , and this number has risen since $1980 .{ }^{1}$ Obesity is most often assessed using the body mass index (BMI), ${ }^{23}$ which has proven to increase in parallel with the risk of cardiovascular diseases (CVDs) such as coronary heart diseases or strokes. ${ }^{4}$ However, the BMI provides limited information on body fat distribution, which is related to metabolic risk. ${ }^{45}$ The majority of fat is stored in the subcutaneous adipose tissue even though, in some individuals, excessive amounts may be accumulated intra-abdominally (visceral fat). ${ }^{2}$ The visceral accumulation of body fat is due to genetic factors, ${ }^{6-12}$ neuroendocrine perturbations ${ }^{13}$ and environmental and lifestyle factors. ${ }^{14}$ The combination of over consumption of energy-dense food and a sedentary lifestyle are well known to play a role in the accumulation of visceral fat. ${ }^{21516}$ The BMI alone seems 
insufficient to assess the distribution of body fat and evaluate the cardiometabolic risk among adults with excess of adiposity, because the BMI fails to capture the cardiometabolic risk related to abdominal obesity. ${ }^{17}$ Abdominal obesity is responsible for increased risk of insulin resistance, type 2 diabetes mellitus, metabolic syndrome, CVDs, cancers, chronic respiratory diseases and all-cause mortality. ${ }^{218-22}$

Three anthropometric proxies are commonly used to assess abdominal obesity: waist circumference (WC), waist-to-height ratio and waist-to-hip ratio. Most studies on abdominal obesity have used WC as the defining criterion. $^{2}{ }^{2324}$ The WC is known to be sensitive to visceral fat accumulation. ${ }^{25}$ Individuals with a larger WC have more abdominal fat than those with a smaller WC. ${ }^{25}$ The threshold of WC used to define abdominal obesity depends on ethnic groups and the world's regions. For sub-Saharan Africa (SSA), WHO defined abdominal obesity by fixing sex-specific WC cut-off points at $\geq 94 \mathrm{~cm}$ for men and $\geq 80 \mathrm{~cm}$ for women. ${ }^{4}$ This cut-off point appears to increase the risk of metabolic complications. Furthermore, the risk of cardiometabolic disorders is 'substantially increased' when the WC is $\geq 102 \mathrm{~cm}$ among men and $\geq 88 \mathrm{~cm}$ among women. ${ }^{4}$ Using the WHO definition, Wong et $a l^{26}$ reported that nearly half $(41.5 \%)$ of the global adult population was abdominally obese and that this prevalence is rising worldwide, including in lowincome and middle-income countries in SSA. However, there is little data on abdominal obesity in SSA as previously highlighted by Wong et al. ${ }^{26}$ Some studies have been conducted in South Africa, ${ }^{27}$ Kenya, ${ }^{28}$ Uganda, ${ }^{29}$ Nigeria $^{30}$ and Cote d'Ivoire. ${ }^{31}$ Apart from that of Kabwama et $a l^{29}$ in Uganda, most of these studies were conducted in local areas and, therefore, do not provide country-level estimates for the prevalence of abdominal obesity. The new consensus of the International Atherosclerosis Society (IAS) and the International Chair on Cardiometabolic Risk (ICCR) Working Group on Visceral Obesity, published in March 2020, concluded that decreasing WC is a critical target to reduce the cardiometabolic complications for both sexes. ${ }^{17}$

A recent population-based nationwide study in Burkina Faso has shown a high proportion (one out of five) of adults with abnormal weight. ${ }^{32}$ In Northern Ouagadougou, Zeba et $a l^{33}$ noted that the prevalence of abdominal obesity was $12.5 \%$. In their study of specific populations in Bobo-Dioulasso, Marceline $e t a l^{34}$ found out that $64.9 \%$ of diabetics were abdominally obese. These studies, however, do not provide information on the nationwide prevalence of abdominal obesity. As is the case in many other developing countries, the management of cardiometabolic risk factors is becoming a public health challenge in Burkina Faso. ${ }^{35}$ The added value of our study comes from our focus on the prevalence of abdominal obesity, predictors and its association with CVD risk among the adult population of Burkina Faso using data from the first national non-communicable disease $(\mathrm{NCD})$ risk factors survey.

\section{METHODS}

\section{Study design, setting and population}

We conducted a secondary analysis of data from a crosssectional survey, the national WHO STEPS survey aimed at assessing the risk factors for NCDs. This survey was carried out between 26 September and 18 November 2013 in Burkina Faso. Burkina Faso is located in the SSA region in West Africa, covering a total surface area of $272960 \mathrm{~km}^{2}$ with 20870060 habitants in 2019, with life expectancy at birth of 61.8 years. The proportion of the population living in the urban area increased (according to the results of the last national population census), from $12.7 \%$ in 1985 to $22.7 \%$ in 2006 . The epidemiological profile is dominated by infectious diseases. Moreover, there is an increasing burden of NCDs, including CVDs, resulting in the country facing a double burden of diseases and progressive change in the pattern of diseases. The data used in our study were collected from a representative sample of adults between 25 and 64 years old. The study was designed to provide estimates at the national and regional levels, as well as places of residence (urban/rural). Participants were selected using a threestage cluster stratified sampling method. A total of 240 enumeration areas (EA) were selected. Then, in each EA, 20 households were randomly selected. One respondent was identified in each household. ${ }^{36}$

\section{Data collection}

Data were collected electronically on a Personal Digital Assistant and consisted in face-to-face interviews, conducted after obtaining the informed consent of the respondent. Risk factors linked to NCDs, such as physical activity and biochemical parameters of the subjects selected to participate in the survey were collected using a STEPS instrument. The survey procedures involved three steps: the first step focused on sociodemographic information, behavioural measures and factors regarding physical activity, food hygiene, oral health and knowledge of NCD risk factors. Behavioural measures bordering on the consumption of tobacco and alcohol were also collected. The second step measured the following physical parameters: height was measured using a portable measuring rod for participants wearing neither shoes nor hats. Weight was measured using an electronic weighing scale (SECA) with the person being weighed lightly clothed, without shoes. The WC (umbilical perimeter) was measured using a measuring tape applied directly to the skin along the axillary line, midway in between the lower base of the last rib and the iliac crest of each side; the measurement was taken only once and rounded of the nearest $0.1 \mathrm{~cm}$. Participants were ineligible for waist measurement if they were pregnant. Blood pressure was measured using an electronic sphygmomanometer. The third step was to measure blood sugar level and blood cholesterol from a capillary blood sample using an electronic device, CardioChek. Data were collected by graduate medical, nurses and student nurses. 
Variables of interest

\section{Outcome variable}

In our study, the dependent variable was abdominal obesity, which was measured using the WC for each of the study participants. For the primary outcome, that is, the cut-off, a WC of $\geq 94 \mathrm{~cm}$ for men and $\geq 80 \mathrm{~cm}$ for women were used. To estimate the proportion of adults who needed to reduce their weights, we used a cut-off of WC $\geq 102 \mathrm{~cm}$ for men and $\geq 88 \mathrm{~cm}$ for women as a secondary outcome, as recommended by Lean et al. ${ }^{37}$ This corresponds to a very high WC. ${ }^{38}$

\section{Explanatory variables}

To take into consideration the influence of potential predictors on the WC, based on previous studies, ${ }^{27} 2939$ we selected the following sociodemographic, behavioural and metabolic factors:

- Sociodemographic factors: Regarding the demographic factors, we categorised all the variables. Among these variables are the following: age (25-34, 35-44, 45-54, 55-64 years), sex (male/female), highest education level (no level, primary, secondary or higher), marital status (single/married), professional status (wage earner, self-employed, unemployed) and place of residence (urban/rural).

- Behavioural factors: The behavioural variables that could influence our dependent variable selected for our study are the following: smoking status (yes/no), alcohol use (yes/no), number of fruits or vegetables eaten per day, type of fat intake and physical activity (high, moderate and low intensity).

- Metabolic factor: We used the height and weight of the individuals to obtain their BMI and then categorised it into four groups (BMI $<18.5=$ underweight; $18.5 \leq \mathrm{BMI}<25=$ normal; $\mathrm{BMI} \geq 25=$ overweight; $\mathrm{BMI}$ $\geq 30$ = obesity). We also checked the association between abdominal obesity and other cardiovascular intermediate risk factors such as high blood pressure (HBP) as defined by the WHO (systolic blood pressure $\geq 140 \mathrm{~mm} \mathrm{Hg}$ or diastolic blood pressure $\geq 90 \mathrm{~mm} \mathrm{Hg}$ ) and diabetes (capillary fasting blood glucose above or equal $6.1 \mathrm{mmol} / \mathrm{L}$ ) and hypercholesterolaemia (capillary total cholesterol above or equal $5.2 \mathrm{mmol} / \mathrm{L}$ ).

\section{Cardiovascular health risk assessment}

In this study, to assess cardiovascular health risk, we used the National Institute for Health and Clinical Excellence (NICE) BMI-WC matrix approach, which combines the BMI and WC values to define different levels of health risk. $^{38}$

\section{Statistical method}

We first described the characteristics of the study population through a weighted analysis to take into account the sampling design. Standardisation was achieved using the age structure of the adult population of Burkina Faso in $2013 .{ }^{40}$ We implemented a modified Poisson regression model using a generalised estimating equation to evaluate the association between abdominal obesity (primary outcome) and sociodemographic, behavioural and biological characteristics of the study population. With this model, we derived the prevalence ratios (PRs) and $95 \%$ CI. The covariates were used in the multivariable analysis based on the epidemiological plausibility and their contributions to the model. For the secondary outcome (very high WC), only the overall results and disparities by sex and residence were presented in the text. Statistical significance was accepted at the 5\% level $(\mathrm{p}<0.05)$. all analysis was done using Stata v15.1.

\section{Patient and public involvement}

Patients or the public were not involved in the design, conduct, reporting or dissemination the plans of our research.

\section{RESULTS}

Sociodemographic characteristics of the study population

A total of 4308 participants with valid WC and BMI data were included in this study (figure 1). The mean age was $38.5 \pm 11.2$ years and $41 \%$ of participants were aged between 25 and 34 years, $52.4 \%$ were female and $74.1 \%$ were living in rural areas. People with no formal education represented $78.6 \%$ of the participants (see table 1 for more details).

\section{Prevalence of abdominal obesity}

Among the 4308 participants, 876 had abdominal obesity. As shown in table 2, the overall age-standardised prevalence of abdominal obesity (primary outcome) was $22.5 \%$ (95\% CI $21.3 \%$ to $23.7 \%$ ). This age-standardised prevalence was $35.9 \%$ (95\% CI $33.9 \%$ to $37.9 \%$ ) among women and $5.2 \%$ (95\% CI $4.3 \%$ to $6.2 \%$ ) among men. The prevalence increased with the age groups as follows: $19.6 \%$ (95\% CI $17.1 \%$ to $22.4 \%$ ) for $25-34$ years, $24.0 \%$ (95\% CI $20.8 \%$ to $27.6 \%$ ) for $35-44$ years, $25.7 \%$ (95\% CI $21.5 \%$ to $30.3 \%$ ) for $45-54$ years; $25.3 \%$ (95\% CI $20.8 \%$ to $30.6 \%$ ) for 55-64years. No difference was observed regarding marital status, and the age-standardised prevalence of abdominal obesity among married people was $22.5 \%$ (95\% CI $21.2 \%$ to $23.8 \%$ ) and $23.6 \%(95 \%$ CI $19.7 \%$ to $27.5 \%$ ) among the unmarried. The agestandardised prevalence of abdominal obesity was $19.4 \%$ (95\% CI $18.1 \%$ to $20.7 \%$ ) among people who had not attended formal school and $33.4 \%$ (95\% CI $29.5 \%$ to $37.2 \%$ ) for people who had attended primary school and $45.8 \%$ (95\% CI $39.8 \%$ to $51.8 \%$ ) for people who had attended at least secondary school. In urban areas, the age-standardised prevalence of abdominal obesity was $42.8 \%$ (95\% CI $39.9 \%$ to $45.7 \%)$ as against $17.0 \%$ (95\% CI $15.7 \%$ to $18.2 \%)$ in rural areas. Among women, the age-standardised prevalence of abdominal obesity in urban areas was $64.4 \%$ (95\% CI $60.1 \%$ to $68.7 \%$ ) as against $27.8 \%$ (95\% CI $25.6 \%$ to $29.9 \%$ ) in rural areas. Among men, it was $14.8 \%$ (95\% CI $11.3 \%$ to $18.4 \%$ ) in 


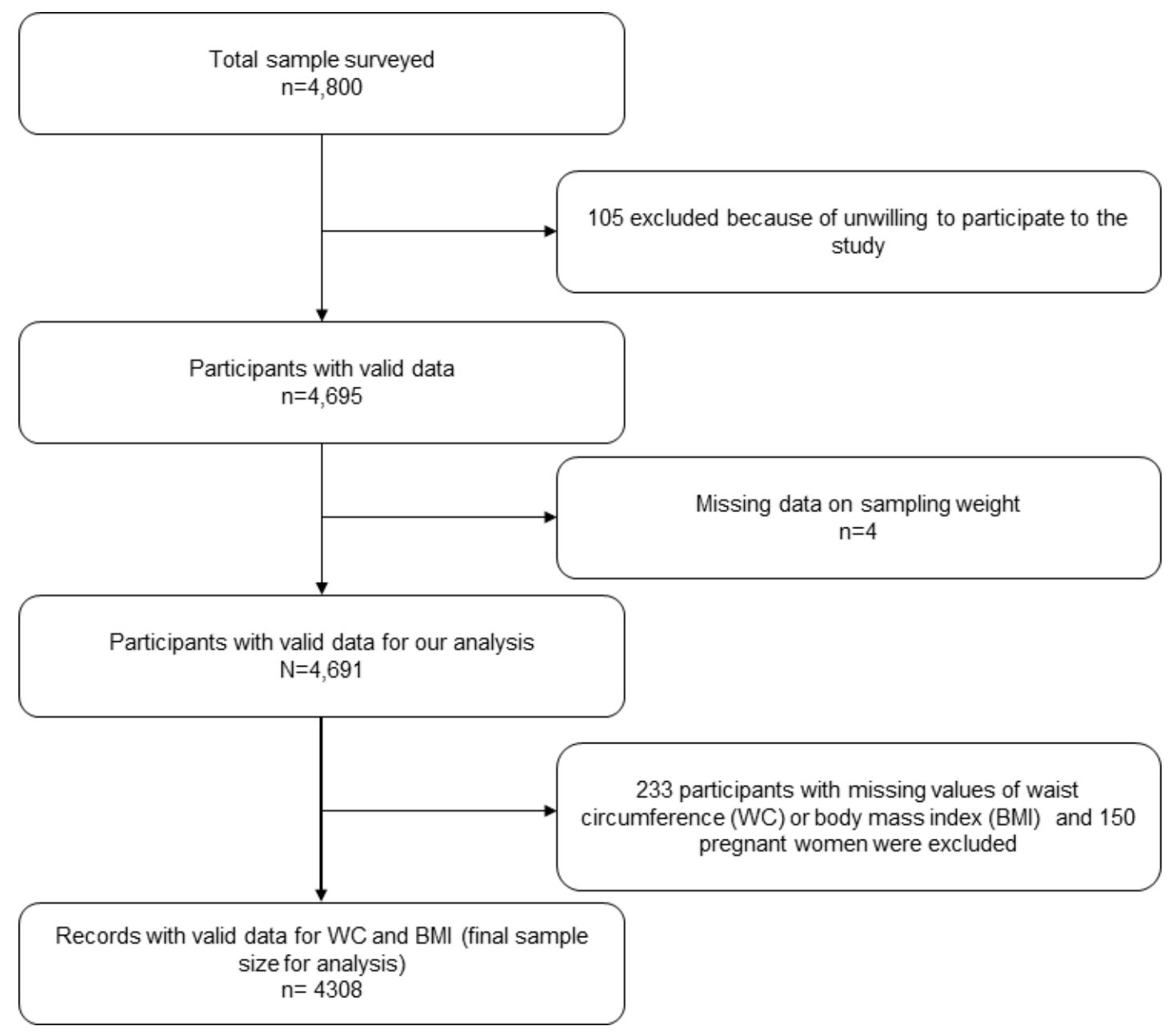

Figure 1 Flow chart of study participants.

urban areas and $3.1 \%$ (95\% CI $2.3 \%$ to $3.9 \%$ ) in rural areas.

Regarding very high WC (secondary outcome) the age-standardised prevalence was $10.2 \%$ (95\% CI 9.3\% to $11.1 \%$ ). It was $16.9 \%$ (95\% CI $15.3 \%$ to $18.5 \%$ ) among women and $1.6 \%$ (95\% CI $1.1 \%$ to $2.1 \%$ ) among men. Regarding residence, we found that the age-standardised prevalence of very high WC was $25.3 \%$ (95\% CI $22.7 \%$ to $28.0 \%$ ) in urban areas and $6.0 \%$ (95\% CI $5.2 \%$ to $6.8 \%)$ in rural areas .

\section{Factors associated with abdominal obesity}

Table 3 shows the results of the multivariable analysis. The main variables found to be associated with abdominal obesity are sex, age group, marital status, education, profession and residence. When the analysis was stratified by sex, we found out that among women, age group, marital status, education and residence were significantly associated with abdominal obesity, while among men, only age group and residence were significantly associated with abdominal obesity (see table 3 for more details).
Association between abdominal obesity and cardiovascular risk factors

After adjusting for the sociodemographic and behavioural characteristics of the study population, we found that abdominal obesity was significantly associated with HBP and hypercholesterolaemia. The prevalence of abdominal obesity was 1.3 times (adjusted Prevalence Ratio (aPR)): 1.30; 95\% CI 1.14 to 1.47) higher among people with HBP, compared with those without (table 3). Besides, the prevalence of abdominal obesity was 1.5 times (aPR: 1.52; $95 \%$ CI 1.18 to 1.94) higher among participants with hypercholesterolaemia.

\section{Cardiovascular health risk assessment}

Using the NICE BMI-WC matrix to assess health risk, we found that the prevalence of 'increased risk', 'high risk' and 'very high risk' to health were $6.8 \%, 4.6 \%$ and $3.2 \%$, respectively. The prevalence of at least increased risk to health was $14.6 \%$ (see table 4 for more details) and $83.6 \%$ of study population was classified as having 'low health risk'. 
Table 1 Sociodemographic, behavioural and biological characteristics of the study population

\begin{tabular}{|c|c|c|}
\hline Characteristics & Number & Percentage* $^{*}$ \\
\hline Sex & 4308 & \\
\hline Women & 2151 & 52.4 \\
\hline Men & 2157 & 47.6 \\
\hline Age group, years & 4308 & \\
\hline $25-34$ & 1917 & 41.0 \\
\hline $35-44$ & 1078 & 27.8 \\
\hline $45-54$ & 796 & 19.2 \\
\hline $55-64$ & 517 & 12.0 \\
\hline Marital status & 4303 & \\
\hline Single & 601 & 12.8 \\
\hline Married & 3702 & 87.2 \\
\hline $\begin{array}{l}\text { Highest completed level of } \\
\text { education }\end{array}$ & 4300 & \\
\hline No formal education & 3380 & 78.6 \\
\hline Primary school & 652 & 14.9 \\
\hline Secondary or higher & 268 & 6.5 \\
\hline Profession & 4303 & \\
\hline Wage earner & 210 & 5.2 \\
\hline Self-employed & 3088 & 68.9 \\
\hline Unemployed & 1005 & 25.9 \\
\hline Residence & 4308 & \\
\hline Urban & 878 & 25.9 \\
\hline Rural & 3430 & 74.1 \\
\hline
\end{tabular}

\begin{tabular}{lrr}
\hline Risk factors & \\
\hline Current smoker & 4307 & \\
$\quad$ No & 3760 & 88.4 \\
\hline Yes & 547 & 11.6 \\
\hline Current drinker & 4307 & \\
\hline No & 3107 & 72.1 \\
\hline Yes & 1200 & 27.9 \\
\hline Fruit and vegetable intake & 4010 & \\
\hline$<5$ & 3819 & 95.7 \\
\hline$\geq 5$ & 191 & 4.3 \\
\hline Type of fat most commonly & 4197 & \\
\hline used & & \\
\hline Vegetable oil & 2620 & 63.3 \\
\hline Butter, lard or fat, margarine & 1157 & 27.2 \\
\hline None or other & 420 & 9.5 \\
\hline Physical activity & 4307 & \\
\hline Intense & 2639 & 60.6 \\
\hline Moderate & 1110 & 25.5 \\
\hline Low & 558 & 13.9 \\
\hline BMl class & 4308 & \\
\hline Underweight & 494 & 11.9 \\
\hline Normal & 3095 & 70.2 \\
\hline Overweight & 548 & \\
\hline & & \\
\hline & & \\
\hline
\end{tabular}

Continued
Table 1 Continued

\begin{tabular}{lcc}
\hline Characteristics & Number & Percentage $^{*}$ \\
\hline Obese & 171 & 4.5 \\
HBP & 4305 & \\
No & 3441 & 76.9 \\
Yes & 864 & 20.1 \\
Diabetes & 4245 & \\
No & 4052 & 95.4 \\
Yes & 193 & 4.6 \\
Hypercholesterolaemia & 4283 & \\
No & 4190 & 97.8 \\
Yes & 93 & 2.2 \\
\hline
\end{tabular}

*Weighted percentage. The missing data for some variables corresponds to non-responses for these questions during the STEP survey.

$\mathrm{BMI}$, body mass index; HBP, high blood pressure.

\section{DISCUSSION}

This study reported for the first time the countrywide prevalence of abdominal obesity in Burkina Faso considering two cut-offs of WC. The estimate of the prevalence of abdominal obesity are lower than other estimates using the cut-off of $\geq 94 \mathrm{~cm}$ for men and $\geq 80 \mathrm{~cm}$ for women. In the literature, different cut-off points for WC have been used to evaluate abdominal obesity. Indeed, using a cut-off point for WC of $\geq 94 \mathrm{~cm}$ for men and $\geq 80 \mathrm{~cm}$ for women, a recent meta-analysis by Wong et $a l^{26}$ reported that the global prevalence of abdominal obesity was $41.5 \%$ (95\% CI $39.9 \%$ to $43.2 \%)$. This prevalence is higher than those reported in our study using the same WC cut-off point. It is known from Wong $e t a l^{26}$ that the prevalence of abdominal obesity is higher among populations of high-income countries and Caucasians. ${ }^{26}$ In the context of SSA, different prevalence levels of abdominal obesity have been reported using a cut-off of $\geq 94 \mathrm{~cm}$ for men and $\geq 80 \mathrm{~cm}$ for women. Indeed, Owolabi $e t a l^{27}$ noted that the prevalence of abdominal obesity in South Africa was $67 \%$ when using the same cut-off as Wong et $a l^{26}$ The prevalence of abdominal obesity in Kenya was found to be $52.0 \% .^{28}$ A study in Nigeria showed a prevalence of $30.1 \% .^{30}$ Yayehd et at ${ }^{41}$ noted that the prevalence of abdominal obesity was $48.8 \%$ in semiurban areas in Togo. Using the cut-off of $\geq 102 \mathrm{~cm}$ for men and $\geq 88 \mathrm{~cm}$ for women, Kabwama et $a t^{29}$ showed that the prevalence of very high WC in Uganda was $11.8 \%$, which is similar to those reported in our study using the same cut-off point. In SSA, abdominal obesity is seen as a sign of wealth, affluence, respect and dignity. ${ }^{29}$ This harmful perception of abdominal obesity among the adult population of SSA presents a challenge for the implementation of weight management strategies. Considering the mediating role of abdominal obesity in the development of diabetes and cardiovascular and other chronic diseases, coupled with the high prevalence and harmful perception about 
Table 2 Age-standardised prevalence of abdominal obesity based of the characteristics of the study population

\begin{tabular}{|c|c|c|c|c|c|c|}
\hline \multirow[b]{2}{*}{ Characteristics } & \multicolumn{2}{|r|}{ Men } & \multicolumn{2}{|r|}{ Women } & \multicolumn{2}{|r|}{ Total } \\
\hline & $\mathbf{n}$ & Prev $(95 \% \mathrm{Cl})$ & $\mathbf{n}$ & Prev $(95 \% \mathrm{Cl})$ & $\mathbf{n}$ & Prev (95\% Cl) \\
\hline All participants & 2157 & 5.2 (4.3 to 6.2$)$ & 2151 & 35.9 (33.92 to 37.9$)$ & 4308 & 22.5 (21.3 to 23.7$)$ \\
\hline Women & & & & & 2151 & 35.9 (33.9 to 37.9$)$ \\
\hline Men & & & & & 2157 & 5.2 (4.3 to 6.2$)$ \\
\hline $35-44$ & 539 & 8.8 (6.1 to 12.5$)$ & 539 & 38.3 (32.9 to 44.0 ) & 1078 & 24.0 (20.8 to 27.6$)$ \\
\hline $45-54$ & 407 & 6.6 (4.4 to 9.8$)$ & 389 & 44.4 (37.2 to 51.9$)$ & 796 & 25.7 (21.5 to 30.3$)$ \\
\hline $55-64$ & 296 & 9.7 (6.2 to 14.8$)$ & 221 & 43.4 (35.9 to 51.2 ) & 517 & 25.3 (20.8 to 30.6 ) \\
\hline \multicolumn{7}{|l|}{ Marital status } \\
\hline No formal education & 1595 & 3.8 (2.8 to 4.7 ) & 1785 & 31.6 (29.5 to 33.7 ) & 3380 & 19.4 (18.1 to 20.7$)$ \\
\hline Primary school & 389 & 6.1 (3.6 to 8.7$)$ & 263 & 54.5 (47.9 to 61.1$)$ & 652 & 33.4 (29.5 to 37.2$)$ \\
\hline Secondary or more & 165 & 21.9 (15.7 to 28.3 ) & 103 & 63.9 (54.4 to 73.4$)$ & 268 & 45.8 (39.8 to 51.8$)$ \\
\hline \multicolumn{7}{|l|}{ Profession } \\
\hline Wage earner & 152 & 17.8 (11.4 to 24.2 ) & 58 & 64.3 (54.1 to 74.5$)$ & 210 & 44.2 (37.8 to 50.7$)$ \\
\hline Self-employed & 1914 & 4.1 (3.2 to 4.9$)$ & 1174 & 30.8 (28.2 to 33.5$)$ & 3088 & 19.1 (17.6 to 20.6 ) \\
\hline Unemployed & 90 & 9.1 (1.8 to 16.5$)$ & 915 & 39.8 (36.6 to 42.9 ) & 1005 & $26.4(22.7$ to 30.1$)$ \\
\hline \multicolumn{7}{|l|}{ Residence } \\
\hline \multicolumn{7}{|l|}{ Current drinker } \\
\hline No & 1494 & 5.0 (3.9 to 6.1$)$ & 1613 & 36.9 (34.5 to 39.3 ) & 3107 & 22.9 (21.5 to 24.3$)$ \\
\hline Yes & 663 & $6.0(4.1$ to 7.8$)$ & 537 & 34.3 (30.3 to 38.4$)$ & 1200 & 21.9 (19.5 to 24.4$)$ \\
\hline \multicolumn{7}{|l|}{ Fruit and vegetable intake } \\
\hline$<5$ & 1909 & 5.0 (4.0 to 6.0$)$ & 1910 & 35.7 (33.6 to 37.9 ) & 3819 & 22.3 (21.0 to 23.6$)$ \\
\hline$\geq 5$ & 83 & $4.6(0.2$ to 9.0$)$ & 108 & 43.5 (34.6 to 52.5 ) & 191 & 26.5 (21.1 to 31.9$)$ \\
\hline \multicolumn{7}{|l|}{ Type of fat most commonly used } \\
\hline Vegetable oil & 1313 & 7.2 (5.8 to 8.6$)$ & 1307 & 40.8 (38.1 to 43.5$)$ & 2620 & 26.1 (24.5 to 27.7$)$ \\
\hline Butter, lard or fat, margarine & 534 & 1.7 (0.7 to 2.8$)$ & 623 & $27.9(24.4$ to 31.4$)$ & 1157 & 16.4 (14.4 to 18.5$)$ \\
\hline None or other & 232 & 2.1 (0.3 to 4.0$)$ & 188 & 30.3 (23.7 to 36.8 ) & 420 & 17.9 (14.1 to 21.6$)$ \\
\hline \multicolumn{7}{|l|}{ Physical activity } \\
\hline Intense & 1437 & 4.2 (3.2 to 5.2$)$ & 1202 & 36.2 (33.4 to 38.9 ) & 2639 & 22.2 (20.6 to 23.8$)$ \\
\hline Moderate & 468 & 4.3 (2.5 to 6.1$)$ & 642 & 32.6 (28.9 to 36.2 ) & 1110 & 20.2 (18.0 to 22.4$)$ \\
\hline Low & 252 & 12.4 (8.3 to 16.5$)$ & 306 & 41.3 (35.8 to 46.9 ) & 558 & 28.7 (25.1 to 32.3$)$ \\
\hline \multicolumn{7}{|l|}{ BMI class } \\
\hline Underweight & 189 & $1.4(0.0$ to 3.4$)$ & 305 & $8.4(5.4$ to 11.4$)$ & 494 & 5.3 (3.4 to 7.2$)$ \\
\hline Normal & 1652 & 1.5 (0.9 to 2.0$)$ & 1443 & 27.1 (24.8 to 29.4$)$ & 3095 & 15.8 (14.5 to 17.2$)$ \\
\hline
\end{tabular}


Table 2 Continued

\begin{tabular}{|c|c|c|c|c|c|c|}
\hline \multirow[b]{2}{*}{ Characteristics } & \multicolumn{2}{|r|}{ Men } & \multicolumn{2}{|r|}{ Women } & \multicolumn{2}{|r|}{ Total } \\
\hline & $\mathbf{n}$ & Prev $(95 \% \mathrm{Cl})$ & $\mathbf{n}$ & Prev $(95 \% \mathrm{Cl})$ & $\mathbf{n}$ & Prev $(95 \% \mathrm{Cl})$ \\
\hline Overweight & 265 & 19.8 (15.1 to 24.5$)$ & 283 & 85.9 (81.9 to 89.8$)$ & 548 & 57.1 (54.0 to 60.2$)$ \\
\hline \multicolumn{7}{|l|}{ HBP } \\
\hline No & 1686 & 4.0 (3.0 to 4.9$)$ & 1755 & 33.1 (30.8 to 35.3 ) & 3441 & 20.4 (19.0 to 21.7$)$ \\
\hline \multicolumn{7}{|l|}{ Diabetes } \\
\hline No & 2023 & 5.1 (4.1 to 6.1$)$ & 2029 & 35.5 (33.4 to 37.6$)$ & 4052 & 22.2 (20.9 to 23.4 ) \\
\hline Yes & 101 & $6.4(2.1$ to 10.7$)$ & 92 & 44.4 (34.4 to 54.4$)$ & 193 & 27.9 (21.9 to 33.9$)$ \\
\hline \multicolumn{7}{|c|}{ Hypercholesterolaemia } \\
\hline No & 2112 & 5.0 (4.1 to 6.0$)$ & 2078 & 34.5 (32.5 to 36.6 ) & 4190 & 21.6 (20.4 to 22.8$)$ \\
\hline
\end{tabular}

BMI, Body mass index; HBP, High blood pressure; nd, there is only two smokers among women which is too small; Prev, agestandardised prevalence.

abdominal obesity in many SSA countries, there is an urgent need for strategies to raise awareness regarding the health implications of abdominal obesity. ${ }^{27}$ Its high prevalence among some populations in SSA, including Burkina Faso, predicts a future epidemic of cardiometabolic complications if no effective action is taken. The current levels of abdominal obesity among the adult population of Burkina Faso is a wake-up call for policy makers to draft effective weight management strategies for the high-risk groups reported in this study.

The predictors of abdominal obesity reported in this study were similar to those reported by several other previous studies. Indeed, as shown by Wong et $a l,{ }^{26}$ the global prevalence of abdominal obesity is significantly higher among older individuals, female subjects, urban residents, Caucasians and populations of higher income level countries. Kabwama et $a l^{29}$ also found out that the prevalence of abdominal obesity was significantly higher among women and being married, individuals with secondary education and urban dwellers in Uganda. The higher prevalence of abdominal obesity reported among women in many studies in both high-income and lowincome countries appears to have numerous causes. ${ }^{26} 2942$ First, differences in the accumulation of abdominal fat among men and women is well known to be influenced by the differences in the level of steroid hormones between the sexes-these hormones drive body structure during the adolescent age. Second, as shown by some researchers, body fat deposit in adolescents appears to be influenced by genetic and environmental factors, which results in women having increased susceptibility to fat accumulation than men. ${ }^{26} 294$ Third, the amount of abdominal fat tends to increase in women since it is influenced by each pregnancy they carried and the postmenopausal body fat distribution. The high prevalence of abdominal obesity in older individuals compared with the youth is, on the one hand, due to the fact that older individuals are typically physically inactive and therefore, expend less energy than young adults. On the other hand, this situation might also be explained by the well-known lower basal metabolism among older adults which, at that age, contributes to the accumulation of excess body fat due to the increased ratio of energy intake to expenditure. However, the onset of abdominal obesity at an early age appears to be associated with an increased risk of mortality. ${ }^{43}$ This suggests that there is the urgent need for policies to prevent abdominal obesity among young people. ${ }^{26}$ In our study, education level and professional status were significantly associated with abdominal obesity. Education level is a proxy indicator of higher socioeconomic status, which is generally associated with an increased risk of abdominal obesity. ${ }^{45}$ This relation seems to disappear when adjusted for physical activity. ${ }^{44}$ This suggests that there is the need to promote a healthy lifestyle among adults with high levels of education. We reported a high prevalence of abdominal obesity among urban dwellers. Socioeconomic status and urbanisation were associated with a dietary habit of excess fat and calorie intake. They are also known to be associated with lack of physical activity and stressful conditions, which tend to increase cortisol secretion and the risk of abdominal obesity.

This study also reported a high proportion of the adult population to be at a high risk of body fat-related cardiometabolic complications in Burkina Faso. Using the same approach (NICE BMI-WC), Owolabi et $a l^{27}$ reported that nearly $67 \%$ of their study participants in South Africa had an increased risk of cardiometabolic complications. This can be explained by the fact that South Africa is at an advanced stage of epidemiological transition with a heavy burden of overweight and abdominal obesity. ${ }^{27}$ Regarding our findings, it seems that Burkina Faso is at the early stages of the growing trend of over nutrition, which is one of the characteristics of the epidemiological transition. Such a situation 


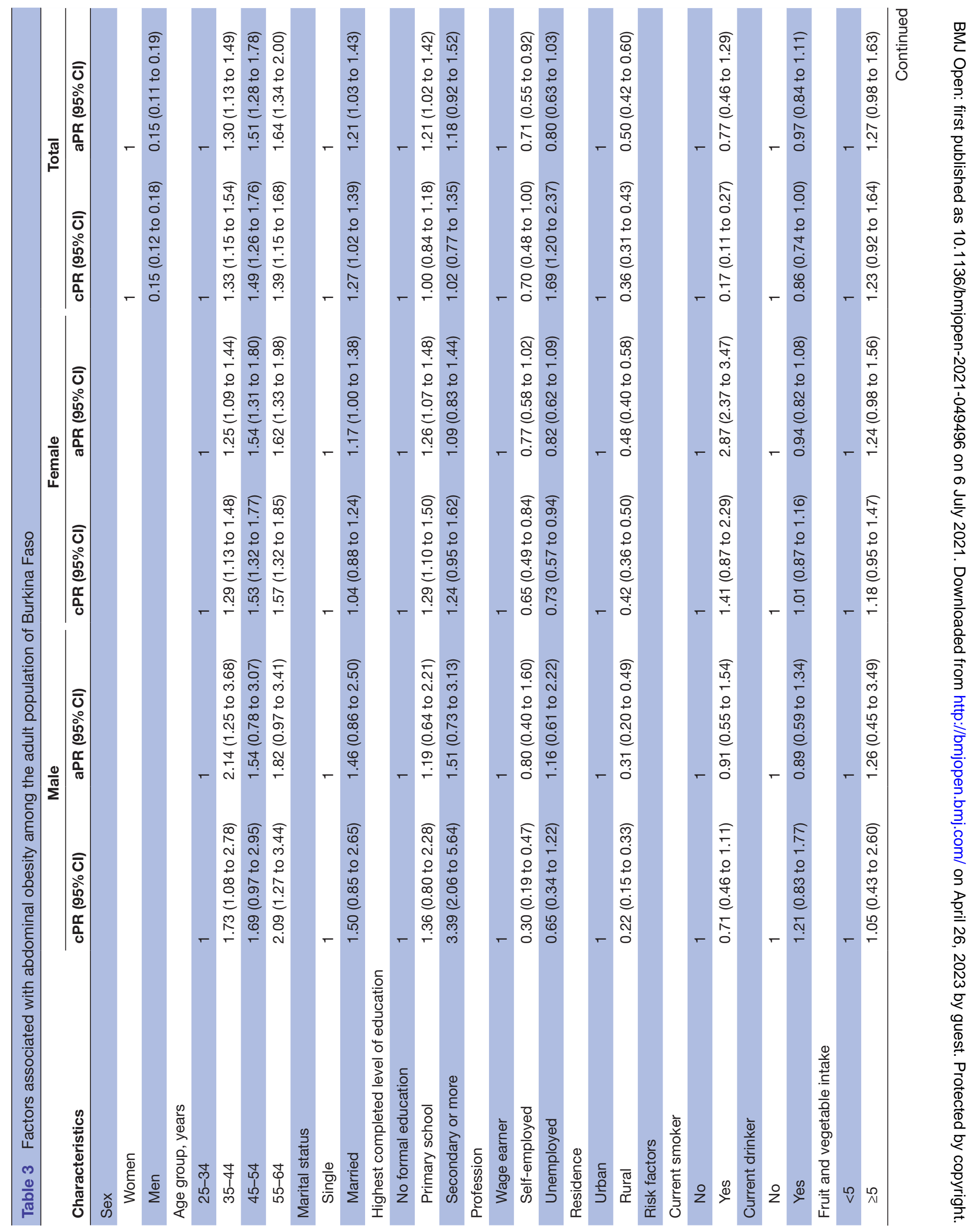




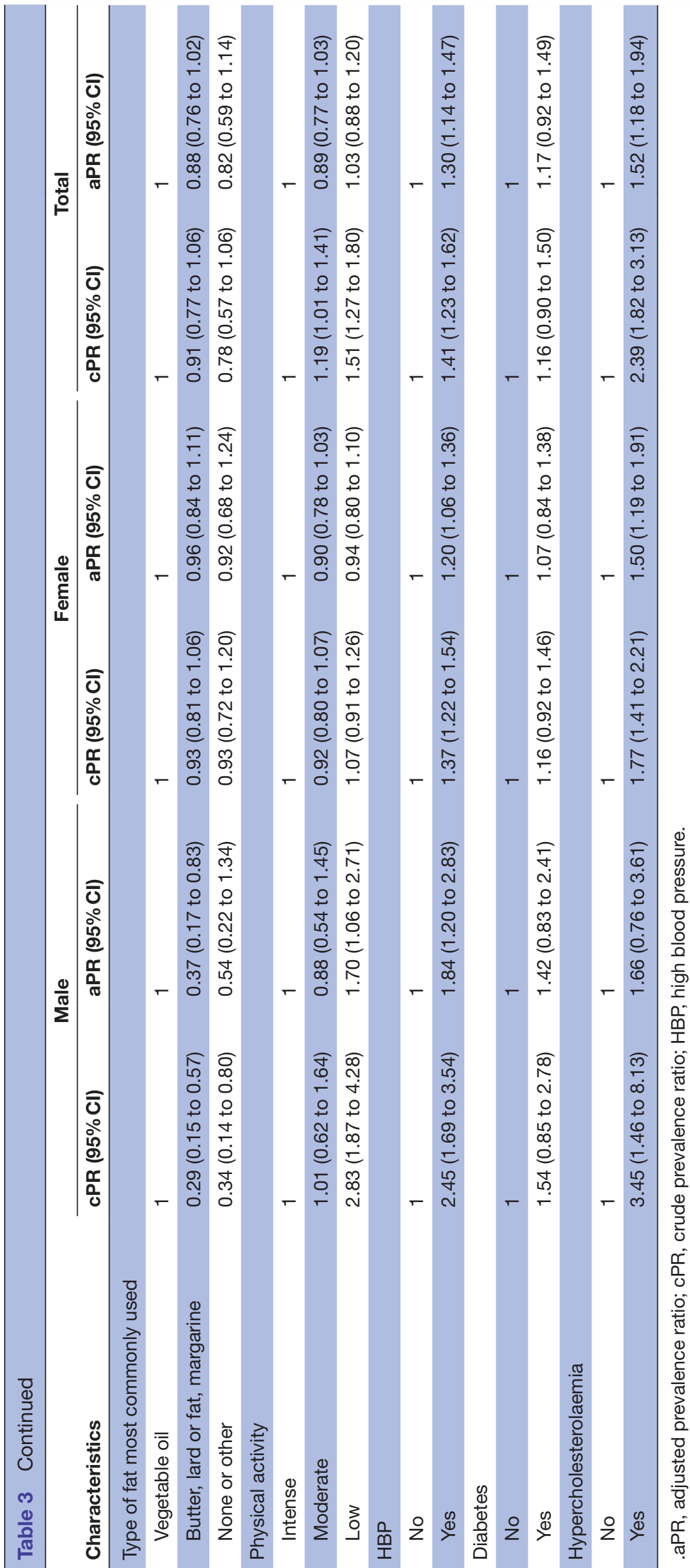

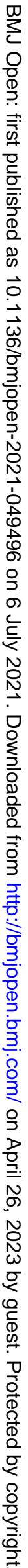


Table 4 Cardiovascular health risk assessment using the NICE BMI-WC matrix

\begin{tabular}{|c|c|c|c|c|}
\hline & & \multicolumn{3}{|c|}{ Waist circumference (WC) } \\
\hline & & Low & High & Very high \\
\hline \multirow[t]{3}{*}{ Body mass index (BMI) class } & Underweight $(<18.5$ kg/m²) & 11.1 & 0.5 & 0.2 \\
\hline & Overweight (25 to <30 kg/m²) & 5.8 & 3.9 & 3.8 \\
\hline & Obese $\left(30\right.$ to $\left.<40 \mathrm{~kg} / \mathrm{m}^{2}\right)$ & 0.5 & 0.8 & 2.7 \\
\hline
\end{tabular}

Low risk, Increased risk, High risk, —Very high risk.

The prevalence of at least increased risk was $14.6 \%$. The prevalence of increased risk, high risk and very high risk of health were $6.8 \%, 4.6 \%$ and $3.2 \%$, respectively.

BMI, body mass index; NICE, National Institute for Health and Clinical Excellence; WC, waist circumference.

offers a unique opportunity to control the prevalence of abdominal obesity and its related health risk before they reach those in the middle-income and high-income countries. This might be achieved through voluntary weight management strategies, which are needed for at least one in every ten adults in Burkina Faso (if we consider the WHO expert consensus). It might also be achieved through routine measurements of WC combined with BMI in clinical practice, as has been recommended by the IAS and ICCR Working Group on visceral obesity. ${ }^{17} \mathrm{WC}$ is known to be associated with cardiovascular and all-cause mortality, regardless of adjustments for BMI. ${ }^{46}{ }^{47} \mathrm{WC}$ is a simple anthropometric measurement which can be easily conducted in settings with limited resources and might help in screening for cardiometabolic risk. ${ }^{17}$ In our study, we found that abdominal obesity was significantly associated with hypertension and hypercholesterolaemia but not with diabetes. The same finding had been noted by Owolabi et al. ${ }^{27}$ In addition, abdominal obesity is known to be an important mediator of insulin resistance and endothelial dysfunction. ${ }^{48}$ Our results might be explained by the fact that many abdominally obese people may not yet have experienced the biological symptoms of insulin resistance. The association between hypercholesterolaemia and abdominal obesity appeared to be confirmed even in the model adjusted for BMI categories. This finding suggests that the WC is an indicator of total cholesterol level particularly among women. The systematic use of the WC measurements in primary healthcare might help in the early diagnosis of women with abdominal obesity and those at risk of CVDs in clinical practice. ${ }^{17}$

The limitations of our study have to be taken into account when discussing its results. First, this study used a cross-sectional design so we cannot make causal interpretations. Second, the behavioural risk factors might be affected by social desirability bias and recall bias. Finally, another limitation of this study is the fact that the measurement of the WC was done only once. However, in spite of these limitations, this study is the first populationbased study with a large sample size in the country on abdominal obesity that was conducted using a standard approach implemented by WHO.

\section{CONCLUSION}

Our study showed a high prevalence of abdominal obesity among adults in Burkina Faso and a high proportion of adults with abdominal obesity who require weight management strategies to prevent the occurrence of cardiometabolic complications. The prevalence was significantly higher among women, the elderly, people with higher educational levels, urban-dwelling adults and those with HBP or hypercholesterolaemia. These findings could be a wake-up call on policy-makers to improve weightloss strategies in the country. Promoting the adoption of a healthy lifestyle and dietary habits might curb the rising household-level and health-system-related costs of cardiometabolic complications associated with abdominal obesity. This is crucial in limited-resource settings, such as in Burkina Faso, to prevent premature health deterioration and encourage sustainable economic growth in a country currently at an early stage of epidemiological and demographic transition.

\section{Author affiliations}

${ }^{1}$ Centre de Recherche en Epidémiologie, Biostatistiques et Recherche Clinique, Ecole de Santé Publique, Université Libre de Bruxelles, Bruxelles, Belgium

${ }^{2}$ Departement Biomédical et Santé Publique, Institut de Recherche en Sciences de la Santé, Ouagadougou, Kadiogo, Burkina Faso

${ }^{3}$ Evaluation Platform on Obesity Prevention, Heart and Lung Institute Research Centre, Quebec, Québec, Canada

${ }^{4}$ Institut National de la Statistique et de la Démographie, Ouagadougou, Kadiogo, Burkina Faso

${ }^{5}$ Institut Africain de Santé Publique, Ouagadougou, Kadiogo, Burkina Faso

Acknowledgements The authors acknowledge Severin Samadoulougou and Bonkoungou Michel for their contribution to data management.

Contributors $\mathrm{KC}$ and $\mathrm{MO}$ analysed the data. $\mathrm{KC}$ and SS wrote the first draft of the manuscript with inputs from M0, SK and FK-S. FK-S and SS conceptualised, formulated research goals, objectives of the study and the lead methodology. FK-S and SK contributed to the acquisition of project financial support. KC, SS, SK and

FK-S contributed to data interpretation and the critical reviewed the manuscript. All authors edited and approved the manuscript.

Funding This work was supported by the Academie de Recherche et d'Enseignement Supérieur (ARES) of Belgium, in the context of a research programme for development, focused on cardiovascular diseases in Burkina Faso: CARDIO-PREV. SS received a postdoctoral fellowship from the Fonds de recherche du Québec Santé (FRQS).

Competing interests None declared. 
Patient and public involvement Patients and/or the public were not involved in the design, or conduct, or reporting, or dissemination plans of this research.

Patient consent for publication Not required.

Ethics approval Before collecting data in the field, the survey protocol was approved by the Ministry of Health's Ethics Committee for Health Research, and the Ministry of Scientific Research and Innovation, and an informed consent was required before the participation of any individual selected for the investigation (Deliberation No. 2012-12-092 of 5 December 2012). The confidentiality of the information collected has been mentioned in the informed consent form. This analysis was also approved by the Ministry of Health's Ethics Committee for Health Research (Deliberation No. 2020-10-231 of 7 October 2020).

Provenance and peer review Not commissioned; externally peer reviewed.

Data availability statement Data are available on reasonable request. Data may be obtained from a third party and are not publicly available. The dataset of the STEPS survey that was used in this research is available at the Ministry of Health on a request addressed to Bicaba Brice: bicaba_brico@yahoo.fr or Zoma Torez : torezo2000@yahoo.fr). All survey materials are available on the WHO website (https://extranet.who.int/ncdsmicrodata/index.php/catalog)

Open access This is an open access article distributed in accordance with the Creative Commons Attribution Non Commercial (CC BY-NC 4.0) license, which permits others to distribute, remix, adapt, build upon this work non-commercially, and license their derivative works on different terms, provided the original work is properly cited, appropriate credit is given, any changes made indicated, and the use is non-commercial. See: http://creativecommons.org/licenses/by-nc/4.0/.

\section{ORCID iDs}

Kadari Cisse http://orcid.org/0000-0003-0219-0197

Sékou Samadoulougou http://orcid.org/0000-0001-9250-1264

Seni Kouanda http://orcid.org/0000-0003-2426-7669

Fati Kirakoya-Samadoulougou http://orcid.org/0000-0002-1326-7367

\section{REFERENCES}

1 The GBD 2015 Obesity Collaborators. Health effects of overweight and obesity in 195 countries over 25 years. N Engl J Med 2017;377:13-27

2 Després J-P. Body fat distribution and risk of cardiovascular disease: an update. Circulation 2012;126:1301-13.

3 Keys A, Fidanza F, Karvonen MJ, et al. Indices of relative weight and obesity. J Chronic Dis 1972;25:329-43.

4 World Health Organization. Waist circumference and waist-hip ratio: report of a who expert consultation, Geneva, 8-11 December 2008. Geneva: World Health Organization, 2011.

5 Park J, Lee ES, Lee DY, et al. Waist circumference as a marker of obesity is more predictive of coronary artery calcification than body mass index in apparently healthy Korean adults: the Kangbuk Samsung health study. Endocrinol Metab 2016;31:559.

6 Riera-Fortuny C, Real JT, Chaves FJ, et al. The relation between obesity, abdominal fat deposit and the angiotensin-converting enzyme gene I/D polymorphism and its association with coronary heart disease. Int J Obes 2005;29:78-84

7 Payab M, Amoli MM, Qorbani M, et al. Adiponectin gene variants and abdominal obesity in an Iranian population. Eat Weight Disord 2017;22:85-90.

8 Fu LW, Zhang MX, Wu LJ, et al. [Gene-gene interaction on central obesity in school-aged children in China]. Zhonghua Liu Xing Bing Xue Za Zhi 2017;38:883-8.

9 Antúnez-Ortiz DL, Flores-Alfaro E, Burguete-García Al, et al. Copy number variations in candidate genes and intergenic regions affect body mass index and abdominal obesity in Mexican children. Biomed Res Int 2017;2017:e2432957

10 Zou Y, Ning T, Shi J, et al. Association of a gain-of-function variant in LGR4 with central obesity. Obesity 2017;25:252-60.

11 Ye D, Cai S, Jiang X, et al. Associations of polymorphisms in circadian genes with abdominal obesity in Chinese adult population. Obes Res Clin Pract 2016;10:S133-41.

12 Huang T, Qi Q, Zheng Y, et al. Genetic predisposition to central obesity and risk of type 2 diabetes: two independent cohort studies. Diabetes Care 2015;38:1306-11.

13 Björntorp P, Rosmond R. Neuroendocrine abnormalities in visceral obesity. Int J Obes Relat Metab Disord 2000;24 Suppl 2:S80-5.

14 Swinburn BA, Sacks G, Hall KD, et al. The global obesity pandemic: shaped by global drivers and local environments. Lancet 2011;378:804-14.
15 Celis-Morales C, Livingstone KM, Affleck A, et al. Correlates of overall and central obesity in adults from seven European countries: findings from the Food4Me study. Eur J Clin Nutr 2018;72:207-19.

16 Sikorski C, Luppa M, Weyerer S, et al. Obesity and associated lifestyle in a large sample of Multi-Morbid German primary care attendees. PLoS One 2014;9:e102587.

17 Ross R, Neeland IJ, Yamashita S, et al. Waist circumference as a vital sign in clinical practice: a consensus statement from the IAS and ICCR Working group on visceral obesity. Nat Rev Endocrinol 2020;16:177-89.

18 Zhang C, Rexrode KM, van Dam RM, et al. Abdominal obesity and the risk of all-cause, cardiovascular, and cancer mortality: sixteen years of follow-up in US women. Circulation 2008;117:1658-67.

19 Chang J-W, Chen H-L, Su H-J, et al. Abdominal obesity and insulin resistance in people exposed to Moderate-to-High levels of dioxin. PLoS One 2016;11:e0145818.

20 Nam GE, Cho KH, Han K, et al. Obesity, abdominal obesity and subsequent risk of kidney cancer: a cohort study of 23.3 million East Asians. Br J Cancer 2019;121:271-7.

21 Alberti G, Zimmet P, Shaw J. The IDF consensus worldwide definition of the metabolic syndrome, 2006. Available: https://www.idf.org/ e-library/consensus-statements/60-idfconsensus-worldwidedefinitionof-the-metabolic-syndrome.html [Accessed 25 Mar 2020].

22 Ezenwaka CE, Okoye O, Esonwune C, et al. High prevalence of abdominal obesity increases the risk of the metabolic syndrome in Nigerian type 2 diabetes patients: using the International diabetes Federation worldwide definition. Metab Syndr Relat Disord 2014;12:277-82.

23 Després J-P, Lemieux I. Abdominal obesity and metabolic syndrome. Nature 2006;444:881-7.

24 Després J-P. Excess visceral adipose tissue/ectopic fat the missing link in the obesity paradox? J Am Coll Cardiol 2011;57:1887-9.

25 Huxley R, Mendis S, Zheleznyakov E, et al. Body mass index, waist circumference and waist:hip ratio as predictors of cardiovascular risk - a review of the literature. Eur J Clin Nutr 2010;64:16-22.

26 Wong MCS, Huang J, Wang J, et al. Global, regional and time-trend prevalence of central obesity: a systematic review and meta-analysis of 13.2 million subjects. Eur J Epidemiol 2020;35:673-83.

27 Owolabi EO, Ter Goon D, Adeniyi OV. Central obesity and normalweight central obesity among adults attending healthcare facilities in buffalo City metropolitan Municipality, South Africa: a cross-sectional study. J Health Popul Nutr 2017;36.

28 Mohamed SF, Haregu TN, Khayeka-Wandabwa C, et al. Magnitude and predictors of normal-weight central obesity- the AWI-Gen study findings. Glob Health Action 2019;12:1685809.

29 Kabwama SN, Kirunda B, Mutungi G, et al. Prevalence and correlates of abdominal obesity among adults in Uganda: findings from a national cross-sectional, population based survey 2014. BMC Obes 2018:5:40.

30 Olatunbosun ST, Kaufman JS, Bella AF. Central obesity in Africans: anthropometric assessment of abdominal adiposity and its predictors in urban Nigerians. J Natl Med Assoc 2018;110:519-27.

31 K. Malik S, Kouame J, Gbane M, et al. Prevalence of abdominal obesity and its correlates among adults in a peri-urban population of West Africa. AIMS Public Health 2019;6:334-44

32 Kaboré S, Millogo T, Soubeiga JK, et al. Prevalence and risk factors for overweight and obesity: a cross-sectional countrywide study in Burkina Faso. BMJ Open 2020;10:e032953.

33 Zeba AN, Delisle HF, Renier G. Dietary patterns and physical inactivity, two contributing factors to the double burden of malnutrition among adults in Burkina Faso, West Africa. J Nutr Sci 2014;3:e50.

34 Marceline TY, Issiaka S, Gilberte KC, et al. Diagnostic et prévalence du syndrome métabolique chez les diabétiques suivis dans un contexte de ressources limitées : cas du Burkina-Faso. Pan Afr Med J 2014;19.

35 Zeba AN, Delisle HF, Renier G, et al. The double burden of malnutrition and cardiometabolic risk widens the gender and socioeconomic health gap: a study among adults in Burkina Faso (West Africa). Public Health Nutr 2012;15:2210-9.

36 Ministère de la santé. Rapport de l'enquête nationale sur la prevalence des principauc facteurs de risques communs aux maladies non transmissibles au Burkina Faso, 2014. Available: https://www.who.int/ncds/surveillance/steps/BurkinaFaso_2013_ STEPS Report.pdf

37 Lean ME, Han TS, Morrison CE. Waist circumference as a measure for indicating need for weight management. BMJ 1995;311:158-61.

38 Tabassum F, Batty GD. Are current UK National Institute for health and clinical Excellence (NICE) obesity risk guidelines useful? crosssectional associations with cardiovascular disease risk factors in a large, representative English population. PLoS One 2013;8:e67764. 
39 Otang-Mbeng W, Otunola GA, Afolayan AJ. Lifestyle factors and co-morbidities associated with obesity and overweight in Nkonkobe Municipality of the eastern Cape, South Africa. $J$ Health Popul Nutr 2017;36:22.

40 INSD. Projection démographique de 20072020 PAR région et Province, 2009.

41 Yayehd K, Pessinaba S, N'cho-Mottoh MPB. Prevalence and Determinants of Adult Obesity in a Low-Income Population of Western Africa: Results from a Nationwide Cross-Sectional Survey. Obesity \& Control Therapies: Open Access, 2017. Available: https:// symbiosisonlinepublishing.com/obesity-control-therapies/obesitycontrol-therapies33.php [Accessed 23 Nov 2020].

42 Agyemang C, Meeks K, Beune E, et al. Obesity and type 2 diabetes in sub-Saharan Africans - Is the burden in today's Africa similar to African migrants in Europe? The RODAM study. BMC Med 2016;14:1-12.

43 Bender R. Effect of age on excess mortality in obesity. JAMA 1999;281:1498.
44 Sarlio-Lähteenkorva S, Silventoinen K, Lahti-Koski M, et al. SocioEconomic status and abdominal obesity among Finnish adults from 1992 to 2002. Int J Obes 2006;30:1653-60.

45 Yoon YS, Oh SW, Park HS. Socioeconomic status in relation to obesity and abdominal obesity in Korean adults: a focus on sex differences. Obesity 2006;14:909-19.

46 Sun Y, Liu B, Snetselaar LG, et al. Association of normal-weight central obesity with all-cause and cause-specific mortality among postmenopausal women. JAMA Netw Open 2019;2:e197337.

47 Pischon T, Boeing H, Hoffmann K, et al. General and abdominal adiposity and risk of death in Europe. N Engl J Med Overseas Ed 2008;359:2105-20.

48 Fezeu L, Balkau B, Kengne A-P, et al. Metabolic syndrome in a subSaharan African setting: central obesity may be the key determinant. Atherosclerosis 2007;193:70-6. 